\title{
The Origins of the Treatment of Traumatic Spinal Injuries
}

\author{
Marie-France Weiner ${ }^{\mathrm{a}} \quad$ John Russell Silver ${ }^{\mathrm{b}}$ \\ ${ }^{a}$ MA History of Medicine, Oxford Brookes University, Oxford, and ${ }^{b} M D, F R C P$ Ed \& Lond, FFSEM (UK), Emeritus \\ Consultant in Spinal Injuries, Stoke Mandeville Hospital, Aylesbury, UK
}

\section{Key Words}

Spinal injury $\cdot$ German medicine $\cdot$ 20th century

\begin{abstract}
Background: It is widely acknowledged that Donald Munro in the United States (1936) and Ludwig Guttmann in the United Kingdom (1944) are the founders of the modern treatment of spinal injuries. However, Germany was the birthplace of neuropathology and led the field in neurology and psychiatry. The first effective spinal injury units were established by Wilhelm Wagner in Königshütte, Silesia and Emil Kocher in Bern, Switzerland at the end of the 19th century. Summary: The modern principles of spinal injury treatment emanated from the work carried out by Wagner and Kocher. This knowledge was applied during the First World War in Germany, France, Austria, Switzerland and the United Kingdom. Marburg established a unit in Vienna, Dr. and Mrs. Déjerine and their team of French doctors treated casualties from the First World War and, in the United Kingdom, Gordon Holmes, George Riddoch and Henry Head treated soldiers suffering from spinal injuries in specialised units. After the war these units closed down, doctors went back to their previous occupations and the expertise gained was lost or, in the case of Germany, suppressed. It was only in 1939 when Ludwig Guttmann, a Jewish refugee, arrived in the United Kingdom that this specialised knowledge was used to set up satisfactory treatment. Key Messages: Many of the key principles of treatment for spinal injuries were developed at the end of the 19th century and during the First World War but units closed down and the knowledge gained was forgotten.
\end{abstract}

With the advent of the Second World War, German refugees, many of whom had worked in the field of neurology (including Ludwig Guttmann), came to the United Kingdom armed with a thorough training in neurology and rehabilitation and applied these principles to the treatment of spinal injuries for the benefit of the country which gave them refuge.

(c) 2014 S. Karger AG, Basel

\section{Introduction}

The development of spinal injury units during the Second World War was one of the success stories of neurological rehabilitation, demonstrating that patients could be kept alive and returned to a useful life.

The successful treatment of spinal injuries is usually attributed to Donald Munro (1936, USA) and Ludwig Guttmann (1944, UK); yet Dr. Kluger, a retired German surgeon, has suggested that the treatment of spinal injuries originated not in the United States or Britain but in Germany before the First World War [1]. He argued that this knowledge was suppressed and forgotten. This paper explores this argument further.

\section{Historical Background}

The first effective spinal unit was established by Wilhelm Wagner (1848-1900) at the end of the 19th century in a place called Königshütte in Germany. Wagner founded the unit to treat injured miners who had sustained spinal inju-

\section{KARGER}

E-Mail karger@karger.com

www.karger.com/ene
(C) 2014 S. Karger AG, Basel

0014-3022/14/0726-0363\$39.50/0
Dr. John Silver

Akeman Business Park

81-82 Akeman Street

Tring, Herts, HP23 6AF (UK)

E-Mail Jrussellsilver@ btconnect.com 


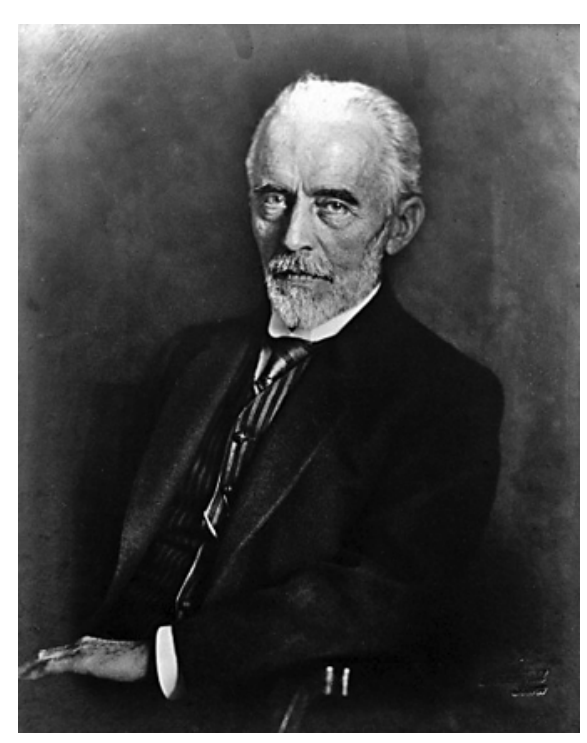

Fig. 1. Theodor Kocher, Bern, Switzerland. Reproduced by the kind permission of the Wellcome Library, London.

ries as a result of collapsed tunnels. Patients were turned regularly and their bladder drained so that early deaths from pressure sores and urinary tract infection could be avoided. Some patients were discharged home but after Wagner's death the unit closed down. Emil Theodor Kocher (18411917), using the same principles, treated spinal injury patients in Bern, Switzerland (see fig. 1) Wagner and Kocher's textbooks became the standard references for the treatment of spinal injuries during the First World War [2,3].

Just as the congregation of injured coal miners led Wagner to found a spinal unit, so the First World War showed that the existing methods of treatment were unsatisfactory as there was no triage and vast numbers of casualties were admitted indiscriminately to general military hospitals. Consequently, all the belligerents established specialised units for the treatment of abdominal wounds, for orthopaedic and plastic surgery, and for spinal injuries [4].

\section{The Treatment of Spinal Injuries during the First World War in Germany (Including all European German-Speaking Countries), France and the United Kingdom}

\section{Germany}

Patients were treated in Vienna by O. Marburg (18741948), E. Ranzi (1875-1939) and A. Eiselberg (18601939), in Tübingen Leipzig by C. Perthes (1869-1927) and Paul Fragenheim (1876-1930), in Berlin by F. Krause (1856-1937), A. Borchard (1864-1940) and R. Cassirer (1868-1925) and in Breslau by Otfrid Foerster (18731941) and Sigmund Weil (1881-1961) [5].

\section{Methods of Treatment}

Doctors recognised that patients with spinal injuries would need lifelong care. Marburg, already a professor of neurology, established a spinal unit in Vienna with a team of specialists in urology, neurology, neurosurgery and orthopaedic surgery. He described the importance of supervising the nursing staff and monitoring the patient's bladder. He incorporated physiotherapy in his treatment regime and endeavoured to return the patients home. With Ranzi, he assessed the benefits of early surgery upon the damaged spinal cord [5].

\section{France}

Casualties suffering from traumatic spinal cord injuries were initially treated in military hospitals and later transferred to two specialised units: namely, first L'Hôpital des Invalides, under the care of Mme Déjerine and her team which included a surgeon, a neurologist and Dr. Hugonet who managed the patient's bladders and pressure sores, and second The Salpêtrière Hospital under the care of Jules Déjerine (1849-1917), George Guillain (1876-1961), Pierre Marie (1853-1940) and Jean Camus (1872-1924) [4].

\section{Methods of Treatment}

French doctors understood the principles of treatment but implementation was lacking due to poor facilities. Although they recognised the importance of draining the bladder by catheterisation, this procedure was left to the nursing staff. Similarly, doctors recognised the importance of preventing pressure sores through regular turning and avoiding urinary maceration of the skin but did not appreciate that when a sore develops, pressure must be relieved. They advocated early transfer to a specialised unit but these principles were not adhered to and consequently soldiers were admitted with pressure sores and urinary infections and most of them perished. In 1916, Guillain and Jean Alexandre Barré (1880-1967) treated 100 soldiers; 82 suffered an immediate death and 18 died within 22 days [6]. Jules Déjerine was in charge of the neurological unit at The Salpêtrière Hospital. His wife, Mme Auguste Déjerine Klumpke (1859-1927), worked with him but later moved to L'Hôpital des Invalides, the 


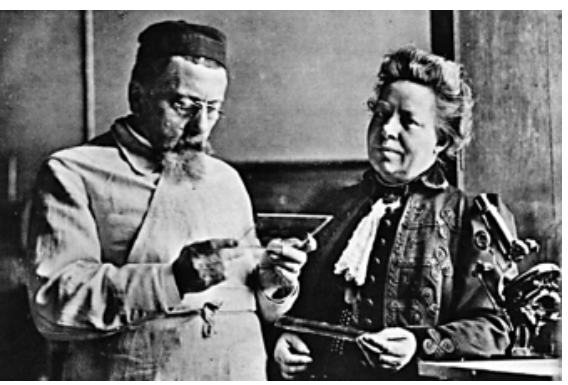

Fig. 2. Dr. and Mrs. Déjerine at The Salpêtrière Hospital, Paris 1929. Reproduced by the kind permission of the Wellcome Library, London.

only specialised spinal unit in France and there she endeavoured to rehabilitate the patients (see fig. 2). Later she worked with Camus in a rehabilitation unit near Fontainebleau [7].

\section{The United Kingdom (UK)}

At the outset of the War, the Regular Army Medical Officers ceased clinical work in order to perform an administrative role. A few doctors were recruited and consultants from the Voluntary Hospitals continued to practise in London while visiting Military Hospitals on a rotating basis. Patients were congregated at the receiving hospitals and transferred to the United Kingdom for treatment but it soon became apparent, just as in the other countries involved in the conflict, that segregation and specialisation were essential to treat head injuries, neurotrauma, spinal injuries, abdominal wounds and orthopaedic injuries [4].

\section{Methods of Treatment}

The lack of a coordinated approach to the treatment of spinal injuries resulted in a high mortality rate because of both ascending infections of the renal tract and the presence of pressure sores $[8,9]$. If they survived the battle field, soldiers with spinal injuries came under the care of Gordon Holmes (1876-1965) in the Military Field Hospitals in France and were transferred to the London Hospital under Henry Head (1861-1940) or to the King George V Hospital under Charles Charters Symonds (1852-1932). Injured officers were transferred to The Empire Hospital in London, a neuro-trauma unit staffed solely by neurologists (among them George Riddoch (1888-1947), Henry Head and Samuel Kinnier Wilson (1878-1937)). The unit lacked a urologist but neverthe-

The Treatment of Traumatic Spinal Injuries less, the results were better than in other hospitals. The fundamentals of treatment were recognised although these were not documented until 1924 with the publication of a Medical Research Council (MRC) instruction manual setting out the key principles of treatment [10].

\section{Overview of the Three Countries}

Despite the hostilities, Germany, France and the United Kingdom all hosted medical conferences on the treatment of spinal injuries and the results of the German conferences were translated into English and widely available. In Germany, where nursing care was meticulous and closely monitored by doctors, the death rates were lower but still deplorable. Marburg recorded 50 deaths out of 150 (33\% mortality) [5]. In France, Guillain and Barré recorded a mortality of $82 \%$, not much worse than that experienced by Symonds in the United Kingdom where $65 \%$ of soldiers died $[6,9]$. In a specialised centre, the patient had a chance of survival but, as Marie advocated, it was vital that the treating doctor regularly supervised the nursing staff so that catheters were changed under strict aseptic conditions and pressure areas inspected regularly [11]. When the War ended the flow of injured soldiers ceased, the military hospitals closed down and important lessons, painfully learned, were forgotten.

\section{Long-Term Medical and Social Care of Surviving Paraplegics after the War}

In Germany, spinal units closed and spinal injury patients were looked after by neurologists and psychiatrists, but the standard of medicine was exceptional. Marburg returned to his professorial unit in Vienna where he treated all forms of neurological disease including paraplegia and he maintained his interest in the subject by writing the section on spinal injuries in the Handbook of Neurology [12]. He also discussed the importance of preventing sporting injuries of the spine. In 1925, an innovative accident hospital opened in Vienna under a gifted visionary surgeon, Lorenz Böhler (1885-1973); his ideas influenced the world, in particular, the accident and emergency movement in Britain [13]. Böhler's clinic was organised meticulously and he supervised all aspects of treatment. There was an interchange of roles whereby nurses and orderlies carried out the work that doctors would usually have undertaken, thereby providing continuity of care. This thus became the forerunner of spinal injury management. Böhler carried out all forms of rehabilitation including that of spinal injury patients. Specialisation was encouraged throughout 
Germany where neurology was well established as a speciality. Foerster set up a comprehensive neurological rehabilitation unit for patients with peripheral nerve injuries.

In France, talented doctors Jean-François Calot (18611944), Marie, Joseph Babinski (1857-1932), Charles Claude (1869-1945), Gustave Roussy (1874-1948), Jean Lhermitte (1877-1959), Guillain and Barré had left their civilian practices to treat injured soldiers in a series of military spinal injury units. After the War, they returned to their original hospitals, Calot to his famous Orthopaedic Institute at Berck sur Plage, Marie, Babinski, Guillain and Camus to The Salpêtrière Hospital, Roussy and Lhermitte to the Hôpital Paul Brousse in Villejuif, Claude to the Hôpital St. Anne, and Barré as head of a neurological unit in Strasbourg. They pursued their interests in neurology but the treatment of spinal injuries was no longer their main focus [14].

While the treatment of injured war veterans was inadequate and limited to massage and electrotherapy (described as 'instrumental orthopaedics'), in contrast to Britain, there were units treating paralysed patients in large hospitals including L'Hôpital des Invalides in Paris, Mme Déjerine's vocational rehabilitation unit near Fontainebleau and Bidou's unit at The Salpêtrière Hospital. Dr. Gabriel Bidou (1878-1959), who trained under Calot, set up the first department for 'Récupération Fonctionnelle' or physical rehabilitation for bedridden disabled patients at the Salpêtrière in 1927 in Guillain's neurology unit [15].

In the United Kingdom, all but one of the military hospitals closed down and doctors returned to their pre-war clinical practices in neurology. The Empire Hospital became a hotel and the King George V Hospital became a warehouse [16]. An exception was the Military Orthopaedic Hospital in Oxford, which was bought by Lord Morris and became the Nuffield Orthopaedic Hospital [17].

Long-term survivors were admitted to the Royal Star and Garter Home where doctors tried to rehabilitate them with physiotherapy but most patients languished there with renal sepsis and pressure sores. The urologist J. Thomson Walker (1871-1937) visited the Royal Star and Garter Home infrequently and Riddoch and Head never went there at all $[4,18]$.

Civilians were cared for in General Hospitals where there was the knowledge to treat the patients but the facilities were lacking and treatment was desultory. The Royal Colleges and the consultants at the Voluntary Hospitals opposed specialisation. Paralysed patients were treated in the first instance by the neurologists at The National Hospital for Nervous Diseases at Queen Square whose interest lay in diagnosis not treatment and there were no beds for long-term rehabilitation. Neurologists were few and far between; they had a low status in the hospital hierarchy and were rarely on the staff of the Voluntary Hospitals. The long-term treatment of paralysed patients was delegated to orthopaedic surgeons who also suffered from a low status within the profession. Most did not hold an appointment at a Voluntary or General Hospital; they worked in specialist hospitals including The Agnes Hunt and Robert Jones Hospital at Oswestry, nursing homes and spas.

\section{Discussion}

During the First World War in Germany, in France and in the United Kingdom, casualties with spinal injuries were treated in designated spinal units where they were congregated under the care of well-trained neurologists and there was a systematic approach to treatment. After the War, with fewer newly injured patients, the spinal units closed down.

Long-term treatment of chronic spinal injury patients in France and the United Kingdom was unsatisfactory despite French attempts at rehabilitation. Merle d'Aubigné (1900-1989) was critical of his French colleagues, describing them as chauvinistic and isolated from the outside world, and eventually the knowledge was lost [19].

During the War, the Germans achieved the best results with regard to the treatment of spinal injuries. They had specialists in neurology, physical medicine and rehabilitation.

\section{The Pre-Eminence of German Medicine and its Influence on the Treatment of Spinal Injuries}

Rehabilitation and the development of spinal injury treatment did not arise as an isolated phenomenon in Germany; it was a reflection of the high status of medicine in society. There was an integrated approach to medicine with professorial departments based on research and teaching [20]. Doctors came from all over the world for training.

\section{Rehabilitation}

Germany was a pioneer in the field of neurology and psychiatry and was the birthplace of neuropathology. Doctors had laid the foundation for rehabilitation treatment and Germany continued its long-standing tradition 


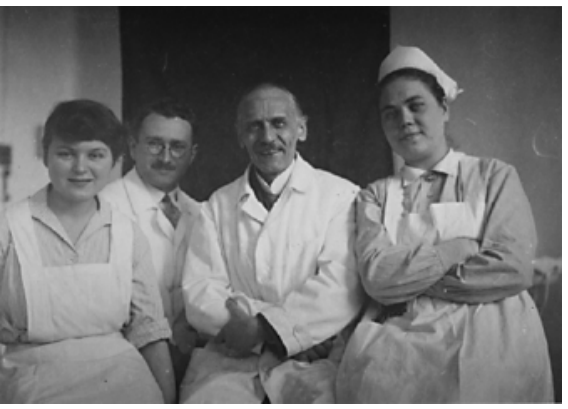

Fig. 3. Otfrid Foerster and Ludwig Guttmann in Breslau. Reproduced by the kind permission of the Wellcome Library, London.

of exercise therapy in between the wars in several innovative rehabilitation departments in Germany and Austria. Heinrich Frenkel (1860-1931), a spa doctor in Switzerland, pioneered rehabilitation by teaching his tabetic patients to walk, using their eyes to compensate for the loss of position sense.

Trained by Frenkel and Carl Wernicke (1848-1905), Foerster's professional thesis was on coordination and he set up the first department of neurology separate from that of psychiatry in Breslau. As Wernicke's assistant, he tried to establish a scientific basis for physical rehabilitation and physiotherapy: 'he caused the lame to walk and the blind to see' [21]. His particular interest in peripheral nerve injuries started during the First World War when he treated 4,748 such patients and operated on 775 . When he returned to his neurosurgical department in Breslau after the War, he treated all forms of neurological disease including spinal injuries. Like Böhler, he recognised the importance of continuity of care and he saw each patient as an experimental model. He examined them before starting treatment and he monitored the results. He investigated the recovery of peripheral nerve function through studies on sweating and thermoregulation. Crucially, Foerster trained Ludwig Guttmann in the management of peripheral nerve injuries and it was this rigorous Prussian training that influenced Guttmann in the founding of the only successful spinal unit in the United Kingdom at Stoke Mandeville Hospital (see fig. 3-5) [22].

\section{The Decline of German Medicine under the Nazis}

German medicine maintained its pre-eminent status until 1933 but after the advent of Hitler there was a dramatic decline in German medicine and the knowledge was lost. Specialisation and specialist hospitals were op-

The Treatment of Traumatic Spinal Injuries posed in favour of general practice. Anyone who did not remain fit and healthy and contribute to the good of the state became a burden on society, 'life unworthy of life', and therefore, the rehabilitation of spinal injury patients was anathema [23]. Under the Nazi regime, unable to practise and fearing for his life and that of his family, Guttmann like many other Jewish doctors fled the country with the aid of the Council for the Assistance of Refugee Academics (CARA).

\section{The Second World War}

Britain drew up plans to treat the many casualties expected, particularly from bombing. Anticipating a short war, Hitler did not make provision for the setting up of spinal units. France rapidly became an occupied country and therefore, could not implement provision for the treatment of soldiers with spinal injuries.

In Britain, at the outset of the Second World War, spinal units were set up all over the country under the direction of four consultants: the neurosurgeons Norman Dott (1897-1973) in Glasgow and Geoffrey Jefferson (18861961) in Manchester, the orthopaedic surgeon, Frank Holdsworth (1904-1969) in Sheffield and the neurologist George Riddoch in the South of England. They visited these units only sporadically and the patients were covered with sores and suffered from urinary sepsis. Nursing staff were inadequate in number and poorly trained and there were no physiotherapists, no occupational therapists and no equipment. Patients were no better after three years than when first admitted [24]. Patients with spinal injuries were scattered around the hospitals and junior resident doctors visited them only after having performed their other clinical duties. A defeatist attitude prevailed. When Robert Lipchitz, Registrar to Professor Dott in Scotland, told him he wanted to look after spinal patients, Dott replied 'of course but after you have finished your other work' [25]. In the spring of 1944, a Dr. Allen was summoned to group headquarters and ordered to open a spinal unit at Leatherhead Hospital and told 'as you know, they are hopeless cases - most of them die but you must do your best for them' [26].

It was only when Guttmann was appointed as the only full-time Resident Medical Officer to Stoke Mandeville that the situation changed. He instituted a Prussian regime in his unit in the Foerster and Böhler tradition of medicine. He trained and supervised the auxiliary and nursing staff and took the overall responsibility for all aspects of patients' care [27]. 
Translation Prom German language.

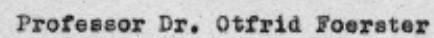

(si gned) Professor Foerster.

Fig. 4. Foerster's reference letter on Ludwig Guttmann. Reproduced by the kind permission of the Wellcome Library, London.

\section{Conclusion}

Ludwig Guttmann lacked practical experience in treating spinal injuries since he was trained in the rehabilitation of patients with peripheral nerve injuries. When he came to the United Kingdom in 1938, he spent five years in Oxford carrying out research; he bitterly resented not being allowed to treat patients. In 1944, Riddoch asked him to lecture at the Royal Society of Medicine on the treatment of peripheral nerve injuries [28]. When he was appointed to Stoke Mandeville Hospital, these principles imparted by Foerster became the bedrock of the treatment of spinal injuries.

This study supports Kluger's contention that the treatment of spinal injuries originated in Germany but was 
suppressed and forgotten. Having led the field in neurology, neurosurgery and rehabilitation, Germany became isolated from the rest of the world during the Second World War and the knowledge was lost. Ludwig Guttmann fled to England and, because of his expertise in the treatment of peripheral nerve injuries, he was put in sole charge of a ward of 'hopeless' patients at the spinal unit at Stoke Mandeville; Spinal injuries was an unpromising and neglected field of medicine. There he applied the principles of treatment he had been taught by Foerster in Breslau for treating spinal injury patients, giving them their lives back. He founded the sports movement as a means of rehabilitation that has straddled the world. Guttmann was not unique [29]. Other Jews including Ernst Chain (1906-1979), Hans Krebs (1900-1981), Bernard Katz (1911-2003) and Otto Loewi (1873-1961) fled Germany and brought their expertise to bear in other fields of science and medicine. What unites them is a thorough scientific training. Armed with a rigorous methodology, they applied their knowledge and their methods to the great benefit of the countries that gave them refuge.

\section{Acknowledgements}

We would particularly like to thank Ruth and Hardy Keinan for their prodigious efforts in researching the doctors in Germany to establish their Jewish origins. We are grateful to Professor Paul Weindling for his time and interest and constructive suggestions. Finally, our thanks go to Dr. Patrick Kluger for inspiring us to research the subject.

\section{Disclosure Statement}

None declared.

\section{References}

1 Personal communication with Dr. Patrick Kluger 2004.

2 Wagner W, Stolper P: Die Verletzungen der Wirbelsäule und des Rückenmarks. Stuttgart, Verlag von Ferdinand Enke, 1898.

3 Kocher TJ: Die verletzungen der wirbelsäule zugleich als beitrag zur physiologie des menschlichen rückenmarks. Mittheilungens $\mathrm{d}$ Grenzgeb d Medicin u Chir 1896;1:416-659.

4 Silver JR: History of the Treatment of Spinal Injuries. New York, Kluwer Academic/ Plenum Publishers, 2003, pp 27, 227-239.

5 Gunshot Injuries of the Spinal Cord. Medical Supplement to the Review of the Foreign Press, 1919, pp 142-149.

6 Guillain G, Barré J-A: Les Plaies de la Moëlle Epinière par Blessures de Guerres. La Presse Médicale 1916;62:497-501.

7 Schurch B, Dollfus P: The 'Déjerines': an historical review and homage to two pioneers in the field of neurology and their contribution to the understanding of spinal cord pathology. Spinal Cord 1988;36:78-86.

8 Vellacott PN, Webb-Johnson AE: Spinal injury with retention of urine - the avoidance of catheterisation. Lancet 1919;1:733-737.

9 Symonds CJ: Laminectomy in gunshot injuries of the spinal cord. Lancet 1917;1:93-98.

The Treatment of Traumatic Spinal Injuries
10 Medical Research Council Privy Council. Injuries of the Spinal Cord and Cauda Equina. London, His Majesty's Stationery Office, 1924.

11 Marie P: Bulletin de l'Académie de Médecine, ed 2. Paris, Masson et Cie, 1915, p 7.

12 Marburg O: Traumatic Injuries of the Spinal Cord; in Foerster O (ed): Handbuch der Neurologie, vol 11, Part 3. Berlin, Otto Julius Springer, 1927-1936.

13 Böhler L: The Treatment of Fractures translated by EW Hey Groves, ed 4. Bristol, Wright, 1935.

14 Wirotius JM: Histoire de la Re-éducation en France in Encyclopédie Médico-Chirurgicale. Paris, Elsevier, 1999.

15 Wirotius JM: Gabriel Bidou (1878-1959): L'Origine des soins des personnes handicapées dans le champs sanitaire. Le Journal de la Nervure Avril 2003;3:1-9.

16 Royal Commission on the Historical Monuments of England NBR No 101173 NGR TQ 311802.

17 Silver JR, Weiner M-F: Sir Ludwig Guttmann: his neurological research and his role in the treatment of peripheral nerve injuries, 19391944. J R Coll Physicians Edinb 2013;43:270277.

18 Thomson Walker JW: The treatment of the bladder in spinal injuries in wars. Proc R Soc Med 1937;30:1233-1240.

19 D'Aubigné M: Surfing the waves: fifty years in the growth of French orthopaedic surgery. Clin Orthop Relat Res 1982;171:1-23.
20 Medawar J, Pike D: Hitler's Gift Scientists who Fled Nazi Germany. London, Richard Cohen Books, 2000, p 3.

21 Haymaker W, Schiller F: The Founders of Neurology, ed 2. Springfield, Illinois, Charles C Thomas, 1970, p 555.

22 Silver JR: The making of Ludwig Guttmann. J Med Biogr 2013;21:229-238.

23 Silver JR: The decline of German medicine: 1933-45. J R Coll Physicians Edinb 2003;33: 54-66.

24 Dick TBS: Rehabilitation in Chronic Traumatic Paraplegia - A clinical study. A thesis presented to the Victoria University of Manchester for the Degree of Doctor in Medicine, 1949.

25 Personal communication with Lipchitz 1964.

26 Allen D: Spinal Unit at the Star and Garter Home. The Cord 1964/5;17:14-16.

27 Silver JR, Weiner M-F: George Riddoch: the man who found Ludwig Guttmann. Spinal Cord 2012;50:88-93.

28 Guttmann L: Discussion on rehabilitation after injuries to the central nervous system. Proc R Soc Med 1941;35:305-308.

29 Silver JR: Ludwig Guttmann (1899-1980), Stoke Mandeville Hospital and the Paralympic Games. J Med Biogr 2012;20:101-105. 